\title{
LOWER BOUNDS FOR THE FIRST ZERO FOR NONLINEAR SECOND ORDER DIFFERENTIAL EQUATIONS
}

\author{
DANIEL C. BiLES
}

Abstract. We consider establishing lower bounds for the first zero of the solution of the nonlinear second order initial value problem

$$
\begin{gathered}
\left(p(x) y^{\prime}(x)\right)^{\prime}+f(x, y(x))=0, x \geqslant 0 \\
y(0)=a>0, \quad y^{\prime}(0)=0 .
\end{gathered}
$$

Using the linear case as a starting point, we prove several of these theorems, comparing them by considering several examples.

Mathematics subject classification (2010): 34C10, 34A34, 34A36.

Keywords and phrases: Second order differential equations, nonlinear differential equations, estimation of a zero.

\section{REFERENCES}

[1] Pedro Almenar And LuCAS JóDAR, An upper bound for the distance between zero and a critical point of a solution of a second order linear differential equation, Computers and Mathematics with Applications 63, (2012), 310-317.

[2] R. C. BRown AND D. B. Hinton, Opial's inequality and oscillation of 2nd order equations, Proceedings of the American Mathematical Society 125 (1997), 1123-1129.

[3] B. J. HARRIS AND Q. KONG, On the oscillation of differential equations with an oscillatory coefficient, Transactions of the American Mathematical Society 347, (1995), 1831-1839.

[4] B. J. HARris, On an inequality of Lypapunov for disfocality, J. Math. Anal. Appl. 140, (1990), 495500.

[5] Man Kam KWong, On Lyapunov's inequality for disfocality, Journal of Mathematical Analysis and Applications 83, (1981), 486-494.

[6] RICHARD R. MOORE, The behavior of solutions of a linear differential equation of second order, Pacific J. Math 5, (1955), 126-145.

[7] William T. Patula, On the distance between zeros, Proceedings of the American Mathematical Society 17, (1975), 247-251. 